Bull. Chem. Soc. Ethiop. 2018, 32(3), 459-467.

ISSN 1011-3924

(c) 2018 Chemical Society of Ethiopia and The Authors

Printed in Ethiopia

DOI: https://dx.doi.org/10.4314/bcse.v32i3.5

\title{
RAMAN SPECTRA OF COPPER, COBALT, AND NICKEL COMPLEXES OF NICOTINIC ACID: EQUILIBRIUM STUDIES
}

\author{
Ahmed E. Fazary ${ }^{1,2^{*}}$, Mutasem Z. Bani-Fwaz ${ }^{1}$, Khaled F. Fawy ${ }^{1}$, Taher Sahlabji ${ }^{1}$, Nasser S. \\ Awwad $^{1}$ and Hisham S.M. Abd-Rabboh ${ }^{1,3}$ \\ ${ }^{1}$ Chemistry Department, Faculty of Science, King Khalid University, Abha 9004, Kingdom of \\ Saudi Arabia \\ ${ }^{2}$ Applied Research Sector, Egyptian Organization for Biological Products and Vaccines \\ (VACSERA Holding Company), 51 Wezaret El-Zeraa St., Agouza, Giza, Egypt \\ ${ }^{3}$ Department of Chemistry, Faculty of Science, Ain Shams University, Cairo 11566, Egypt
}

(Received November 7, 2017; Revised October 8, 2018; Accepted October 18, 2018)

ABSTRACT. This article summarizes the protonation and complexation equilibrium constants of nicotinic acid (NA) using different analytical techniques and software's. Additionally, Raman, IR, and NMR spectra were done for nicotinic acid ligand and for its solid complexes with copper(II), cobalt(II) and nickel(II) metal ions.

KEY WORDS: Nicotinic acid, Potentiometry, Spectrometry, Equilibrium constants

\section{INTRODUCTION}

Nicotinic acid (pyridine 3-carboxylic acid, niacin) is a water-soluble B group vitamin that is derived from pyridine with a carboxyl group at the 3-position [1, 2] (Scheme 1). Nicotinic acid is a digestive aid that helps the body to derive energy from carbohydrates, fats and proteins. This vitamin $\mathrm{B}_{3}$ does not free in the body because human do not have the ability to synthesize enough nicotinic acid. This compound is an essential component of a balanced diet, such as wheat, yeast, pork and beef liver. Although nicotinic acid is present in food, most of the niacin is produced synthetically by chemical oxidation or ammoxidation of alkyl pyridines [1]. In vivo, nicotinic acid is needed to synthesis co-enzymes; nicotinamide adenine dinucleotide (NAD) and nicotinamide adenine dinucleotide phosphate (NADP) that are used by dehydrogenase in tissue respiration [3]. The main function of nicotinic acid is as a lipid lowering agent to prevent heart disease and stoke [4]. As a lipid lowering agent, nicotinic acid works by reducing the amount of LDL and triglycerides that are made by liver. In addition, from several researches it was found that nicotinic acid has unique pharmacological properties for arthritis, asthma, diabetes and antiaging nutrient [3].

The main deficiency disease that caused by lack of nicotinic acid is called pellagra. These diseases affect the gastrointestinal tract, lesions of skin and central nervous system [5]. The symptoms of pellagra are dermatitis, diarrhea and even mental disorder.

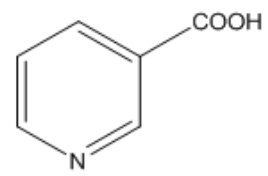

Scheme 1. Structure of nicotinic acid.

*Corresponding author. E-mail: aefazary@gmail.com

This work is licensed under the Creative Commons Attribution 4.0 International License 
The complex formation between nicotinic acid and metal ions has not been studied extensively yet. The protonation constants determination of nicotinic acid has been studied using spectrophotometry. Nicotinic acid has an acid group and a basic group in which the equilibrium of this acid when act as a base is shown in Scheme 2, while the acid equilibrium when act as acid is shown in Scheme 3 [6]. In 1995, Coughlin and Stone [7] studied the adsorption ability of picolinic acid and nicotinic acid to several divalent metal ions. In their result, the authors stated that picolinic acid adsorbs better than nicotinic acid and nicotinic acid is unable to act as chelate for metal ions. Other studies also stated that pyridine-3-carboxylic acids cannot act as chelating ligand, although they can possibly bridge metal atoms in several ways, as shown in Scheme 3 or act as monodentate donors [3, 8]. As a bridging ligand, nicotinic acid has been used to bridge nickel ion in a 3D nicotinic acid bridged nickel polymer. In this kind of 3D structure, nicotinic acid has been found in two different coordination modes. The first mode is bridging mode where each ligand bridges two metal atoms and the second mode is terminal mode where it is bonded to one metal atom only by one of its two carboxyl oxygen atoms [9].

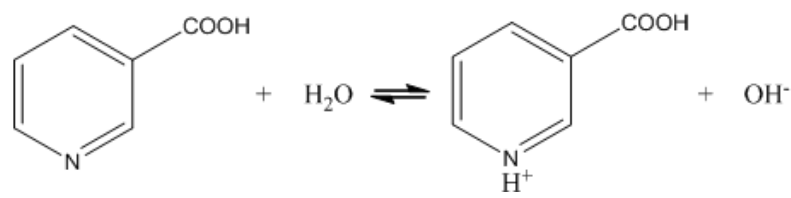

Scheme 2. Nicotinic acid equilibrium when acting as a base.<smiles>O=C(O)c1ccncc1</smiles>

Scheme 3. Nicotinic acid equilibrium when acting as an acid.

The behavior of nicotinic acid as monodentate ligand was also observed in the case of divalent copper complex. An infrared spectra study of nicotinic acid complexes with divalent copper revealed that the carboxyl group of nicotinic acid remains unchanged which indicates that there is no metal to oxygen coordination in this complex. Furthermore, the complex shows appreciable change on the pyridine part of nicotinic acid molecule [10]. Cooper et al. [11] in 1984 publish a research paper which can explain this monodentate behavior of nicotinic acid clearly. They study the structure and biological activity of trivalent chromium and some divalent metal ions coordinated with nicotinic acid for their glucose tolerance factor properties. The interesting part of their result is that they found that only trivalent chromium ion was coordinated to the carboxyl oxygen of nicotinic acid while the other metal ions were coordinated to the pyridine nitrogen of nicotinic acid. They explained these phenomena according to the theory of hard and soft acids and bases (HSAB). Trivalent chromium ion is a hard base so it has preference to coordinated with the carboxyl oxygen which is a hard acid instead of the pyridine nitrogen. On the other hand, all the divalent metal ions they used in their study are soft base, so they will coordinate with pyridine nitrogen of nicotinic acid.

Another report stated that nicotinic acid may also act as a neutral ligand, ligating the metal ion through its $\mathrm{N}$ atom, as found in its copper(I) and gold(III) complexes, or as nicotinate anion that forms complexes with lanthanides of type $\left[\mathrm{Ln}(\mathrm{nic})_{3} .2 \mathrm{H}_{2} \mathrm{O}\right]_{2}(\mathrm{Ln}=\operatorname{Pr}(\mathrm{III}), \mathrm{Gd}(\mathrm{III})$ and $\mathrm{Ho}(\mathrm{III})$ ) by two carboxylate $\mathrm{O}$ atoms forming a four member chelate ring, thus acting as a 
bidentate ligand. Furthermore, three complexes in the silver(I)-nicotinic acid were reported, namely orthorhombic catena-[pyridine-3-carboxylato- $\left.\left(\mathrm{O}, \mathrm{O}^{\prime}\right)\right]$ silver(I), triclinic ammonium bis[pyridine-3-carboxylate-(O,N,N')] silver(I)monohydrate and catena-(hydrogen bis[pyridine-3carboxylato-(N,N')] silver(I)) [12]. The interaction between nicotinic acid and iron has been studied by Appleby and co-workers [13]. They did not determine the stability constants of the complex, but from their results, the effect of nicotinic acid-iron bond can be known from diminished apparent affinity of leghemoglobin for oxygen. This study also compared several ligands which have similar structure with nicotinic acid and found that the high affinity binding of ligand requires an unsubstituted pyridine ring nitrogen atom and an ionized carboxyl group in the 3-position of the ring or on the other hand can be said that nicotinic acid shows higher affinity as compared to the other ligands with similar structure. Urbanska and Podsiadly [3] studied the complex of nicotinic acid and nickel [13] using $\mathrm{pH}$-potentiometric titration and polarographic at $20{ }^{\circ} \mathrm{C}$ in $0.1 \mathrm{M} \mathrm{NaClO}_{4}$ medium. They reported the protonation constant values for first and second protonation of 2.11 and 4.66, respectively, using $\mathrm{pH}$-potentiometric and 2.34 and 4.81, respectively, using polarographic measurement. The authors identified that the interaction between nicotinic acid-Ni [13] is a weak interaction with the stability constant values of $\log \beta_{1}=2.66$ and 3.05 for $\mathrm{pH}-$ potentiometric and polarographic measurement, respectively.
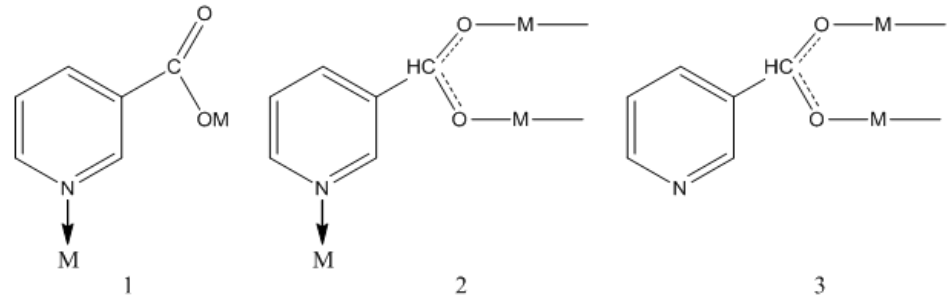

Scheme 4. Possible bridge metal atoms of nicotinic acid.

Also, nicotinic acid complexes of several metal ions [14-18] were investigated using various techniques such as pH-potentiometric titration, polarography, and UV-visible spectrophotometry. The complex formation of divalent transition metal ions (copper(II), cobalt(II) and nickel(II)), and nicotinic acid were recently studied in our laboratory in aqueous solutions using $\mathrm{pH}$-potentiometric technique in the absence and in the presence of glycine peptides and their overall stability constants in aqueous solutions were obtained and explained by the HYPERQUAD 2008 program using the potentiometric data [19-29]. The different representative complex species distribution diagrams were obtained using HYSS 2009 software [19]. The UV-visible spectroscopic, cyclic voltammeteric and conductometric titration measurements were performed to confirm the stoichiometric ratios of metal complexes [19]. The results were supported by quantum chemical calculations [19]. Also, six mixed ligand complexes involving copper(II), cadmium(II), manganese(II), iron(III), nickel(II), and lead(II) metal ions, nicotinic acid, and glycine were synthesized. Full elucidation of the molecular structures for the synthesized mixed ligand complexes were confirmed using detailed spectroscopic IR, ${ }^{1} \mathrm{H}-,{ }^{13} \mathrm{C}-\mathrm{NMR}$, and XRD techniques [20-29]. Furthermore, cytotoxic and antioxidant activities of the synthesized solid complexes were tested to evaluate their bioactivities [20-29].

\section{EXPERIMENTAL}

All chemicals were analytical grade and were used as provided by the suppliers without further purification. Nicotinic acid $(\mathrm{MW}=123.5 ; 98 \%$ purity) was purchased from Sigma Aldrich 
(USA). Metal salts that were used in this investigation are cobalt nitrate hexahydrate $\left(\mathrm{Co}\left(\mathrm{NO}_{3}\right)_{2} \cdot 6 \mathrm{H}_{2} \mathrm{O}\right)$ and nickel chloride hexahydrate $\left(\mathrm{NiCl}_{2} \cdot 6 \mathrm{H}_{2} \mathrm{O}\right)$ from Across Organics (USA), copper chloride dihydrate $\left(\mathrm{CuCl}_{2} \cdot 2 \mathrm{H}_{2} \mathrm{O}\right)$ from Sigma Aldrich (USA). Sodium hydroxide $(\mathrm{NaOH}$, 96\% purity, Yakuri Pure Chemical, Kyoto, Japan) used in titration was first standardized by using potassium hydrogen phthalate (KHP, 99.95\% purity, Sigma Aldrich St. Louis, MO). Hydrochloric acid (37.6\% purity, Fischer Scientific, Bridgewater, NJ) used to acidify the solution was standardized against $\mathrm{NaOH}$. All solutions were prepared freshly before use, using ultra pure water obtained from an ultrapure water system with a resistance of $18.3 \mathrm{M} \Omega \cdot \mathrm{cm}^{-1}$.

Metal-NA binary complexes were synthesized by dissolving ligand NA $(0.12 \mathrm{~g}, 1 \mathrm{mmol})$ in $15 \mathrm{~mL} \mathrm{H}_{2} \mathrm{O}$, the ligand was dissociating by adding a few drops of $5 \mathrm{M} \mathrm{NaOH}$ solution until $\mathrm{pH}$ 11.0 was reached. Five milliliters metal salt in $\mathrm{H}_{2} \mathrm{O}\left(1 \mathrm{mmol}, 0.17 \mathrm{~g} \mathrm{CuCl}_{2} \cdot 2 \mathrm{H}_{2} \mathrm{O}, 0.24 \mathrm{~g}\right.$ $\mathrm{NiCl}_{2} \cdot 6 \mathrm{H}_{2} \mathrm{O}, 0.30 \mathrm{~g} \mathrm{Co}\left(\mathrm{NO}_{3}\right)_{2} \cdot 6 \mathrm{H}_{2} \mathrm{O}$ was added into the ligand solution. The $\mathrm{pH}$ then was adjusted by adding a few drops of $5 \mathrm{M} \mathrm{NaOH}$. The mixture was allowed to react for $6 \mathrm{~h}$ with constant stirring. After reaction, the mixture was filtered to remove any solid residues and the solution was freeze dried, then washed with ethanol and dried in a $50{ }^{\circ} \mathrm{C}$ oven for $4 \mathrm{~h}$. The dried complex was stored in an anhydrous desiccator at room temperature.

Micro-Raman Spectrometer analysis system (Raman RS-2000) with laser source (wavelength $=532 \mathrm{~nm}$ ) at UniNanoTech/UniD2G (National Taiwan University of Science and Technology) was used to analyze the solid complexes. ${ }^{1} \mathrm{H}$ NMR spectra were measured on a Bruker AVIII-600MHz FT-NMR in $\mathrm{D}_{2} \mathrm{O}$ solution. IR spectra were recorded on a Bio-Rad FTS3500 instrument on $\mathrm{KBr}$ disc with spectra range of $400-4000 \mathrm{~cm}^{-1}$.

\section{RESULTS AND DISCUSSION}

Complex between metal ion and ligand can occur since the negative charged ligand tends to bind with the positive charged metal ion. Some of these complexes are known to escalate the biological properties of the original ligand thus triggered many researchers to develop new novel complexes between a biologically active ligand and metal ion (usually the transition metal groups) to improve the ligand biological properties. Several analyses which are frequently used to determine the structure of the complex are elemental analysis, Fourier transform infrared (FTIR) spectroscopy, UV-Vis spectroscopy, nuclear magnetic resonance (NMR), and Raman spectroscopy [30-32]. Additionally, the conductivity and magnetic susceptibility behavior of the compounds were often observed. The conductivity analysis of the compounds helps to determine the electrolyte behavior, while the magnetic susceptibility analysis helps in determining the magnetic behavior. To prove that the synthesized complexes are more beneficial compare to that of the non-metal organic ligand, some in vitro biological activity assays such as antioxidant and antimicrobial activities are popularly employed. The word synthesis refers to production of complex compounds by reactions from simpler compounds. In this work, complex compounds were made by combining ligand NA with transition metal ion. The concept of this synthesis reaction was based on metathesis reaction. Firstly, the $H$ atoms of the ligand donor group were allowed to dissociate by the addition of sodium hydroxide, and the $\mathrm{Na}^{+}$will substitute the $\mathrm{H}^{+}$. Next, metal salt such as $\mathrm{CuCl}_{2}, \mathrm{Zn}\left(\mathrm{NO}_{3}\right)_{2}, \mathrm{NiCl}_{2}, \mathrm{Co}\left(\mathrm{NO}_{3}\right)_{2}$ and $\mathrm{MnCl}_{2}$ was added. Since the divalent charged cation $\left(\mathrm{Cu}^{2+}, \mathrm{Ni}^{2+}\right.$, and $\left.\mathrm{Co}^{2+}\right)$ has higher charge than monovalent $\mathrm{Na}^{+}$ion, thus the ligand tends to bind divalent cation and formed the chelate complex. Overall, the reaction can be written as: $n \mathrm{NaOR}+\mathrm{MCl}_{n} \rightarrow \mathrm{M}(\mathrm{OR})_{n}+n \mathrm{NaCl}$.

Raman spectral data done for nicotinic acid [33] and three of its copper(II), nickel(II), and cobalt(II) metal complexes are given in Table 1 and shown in Figure 1. Nicotinic acid molecule has 14 atoms with 36 normal modes of vibrations and the optimization was done with $C_{s}$ point group symmetry. The 36 normal modes of vibrations are distributed amongst the symmetry species as 25 planar and 11 non-planar vibrations. The $\mathrm{CH}$ stretching vibrations are observed in the range $624-647 \mathrm{~cm}^{-1}$ for the pyridine molecule and like benzene derivatives as in Table 1 . 
Raman spectra of copper, cobalt, and nickel complexes of nicotinic acid; equilibrium studies 463

The ring stretching vibrations are very much important in the spectrum of pyridine and its derivatives and are highly characteristic of the aromatic ring itself (Table 1).

Table 1. Characteristic Raman spectral parameters of nicotinic acid ligand (NA) and its copper(II), cobalt(II), and nickel(II) metal complexes.

\begin{tabular}{|c|c|c|c|c|}
\hline RA assignment & \multicolumn{4}{|c|}{ NA ligand/complex species } \\
\hline & NA & CuNA & NiNA & CoNA \\
\hline$v(\mathrm{C}=\mathrm{O})$ & 1692 & 1692 & 1692 & 1692 \\
\hline$v(\text { ring })_{\text {NA }}$ & 1599 & 1599 & 1605 & 1602 \\
\hline & & & 1634 & 1586 \\
\hline$v(\mathrm{C}-\mathrm{N})$ & & & & 1627 \\
\hline$v(\mathrm{C}-\mathrm{C})$ & 1321 & & & 1389 \\
\hline & 1308 & & 1299 & 1305 \\
\hline$\delta(\mathrm{C}-\mathrm{N})$ & 1202 & 1198 & 1283 & 1241 \\
\hline & 1189 & & 1198 & 1176 \\
\hline$v_{\text {(ring)nic }}$ & 1047 & 1044 & 1186 & \\
\hline$\delta_{(\mathrm{CH}) \text { ring }}$ & 644 & 644 & 1037 & 1034 \\
\hline & & & 644 & 647 \\
\hline
\end{tabular}

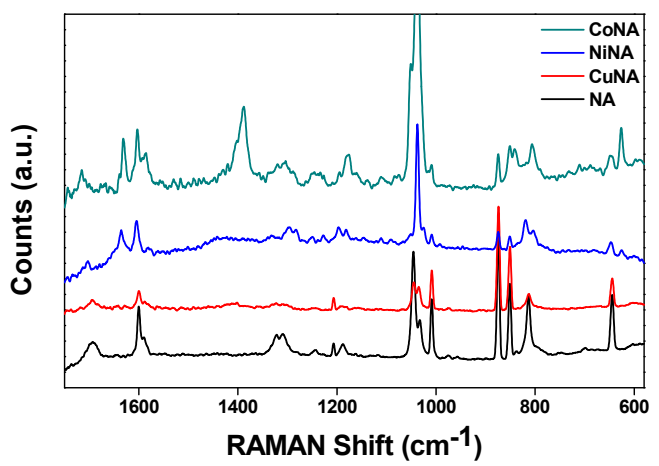

Figure 1. Raman spectral data of nicotinic acid ligand (NA) and its copper(II), cobalt(II), and nickel(II) metal complexes.

The essential infrared spectral absorption patterns of the synthesized complexes are shown in Figure 2. The careful inspection of the IR spectra of free nicotine (NA) ligand [33] and its synthesized binary complexes was made in order to facilitate the assignment of these bands in the free ligand and its metal complexes as shown in the IR charts. It was concluded that, there is not straight regularity in the change of wave numbers of the analyzed bands along with the position of the nitrogen atom in the aromatic ring. That means, electronic charge distribution of the whole molecule differ depending on the position of the nitrogen in the ring in the presence of metal ions. ${ }^{1} \mathrm{H}$ NMR and ${ }^{13} \mathrm{C}$ NMR spectra of free nicotine (NA) ligand and its synthesized copper(II), cobalt(II), and nickel(II) metal complexes could be found in Figure 3. The nuclear magnetic resonance spectral data were recorded in DMSO- $\mathrm{d}_{6}$ for all complexes, taking TMS as internal standards and shown in Figure 3. From the proton and carbon assignments for the free nicotine (NA) ligand and its synthesized metal complexes shown in Figure 2, the comparison between peaks of free ligand and their complexes appeared clearly, in which there are blue shifted in the assignment's values of protons and carbons because of the metal-ligand complex formation. 

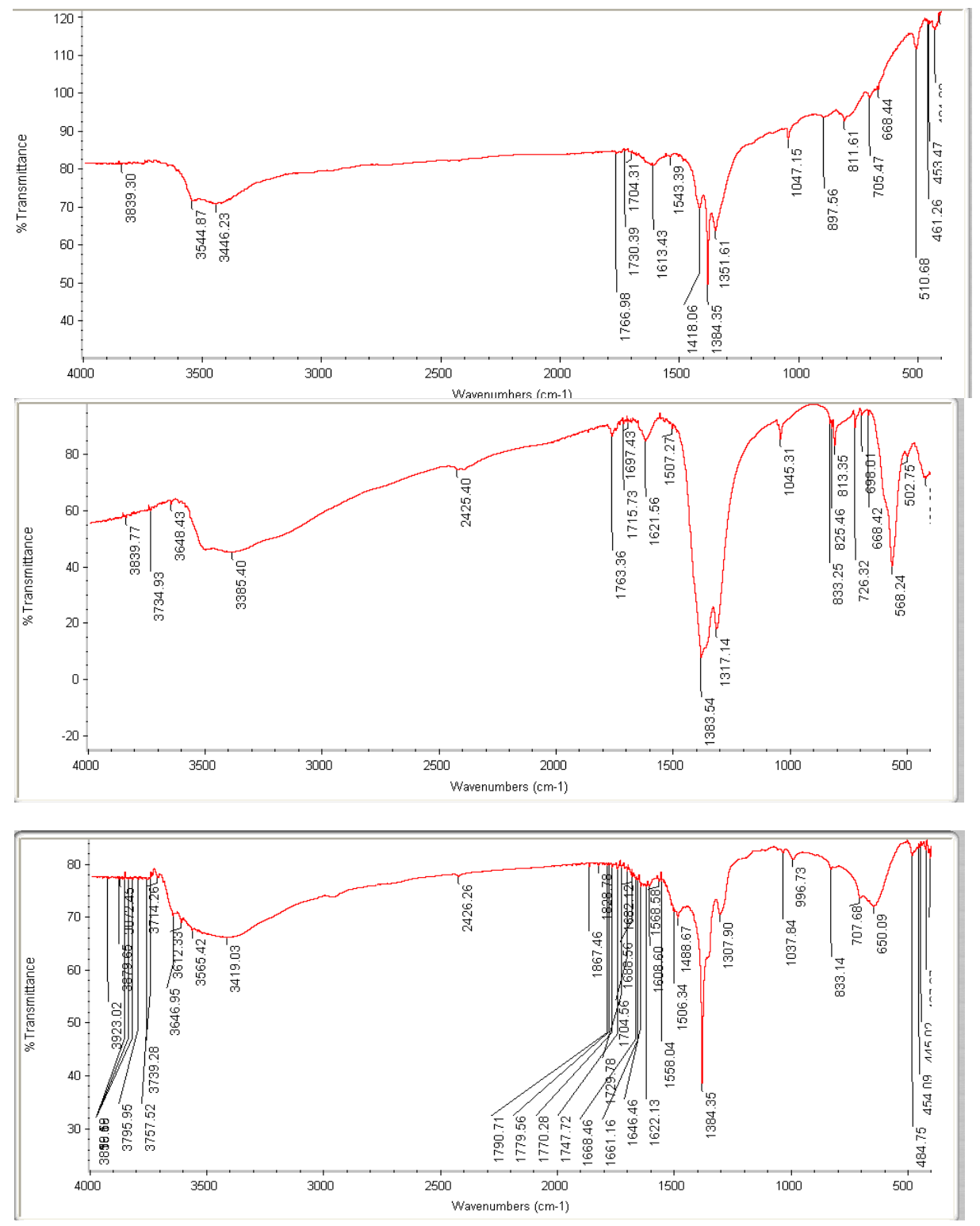

Figure 2. IR Spectral data of copper(II), cobalt(II), and nickel(II) complexes of nicotinic acid (NA). 
Raman spectra of copper, cobalt, and nickel complexes of nicotinic acid; equilibrium studies 465

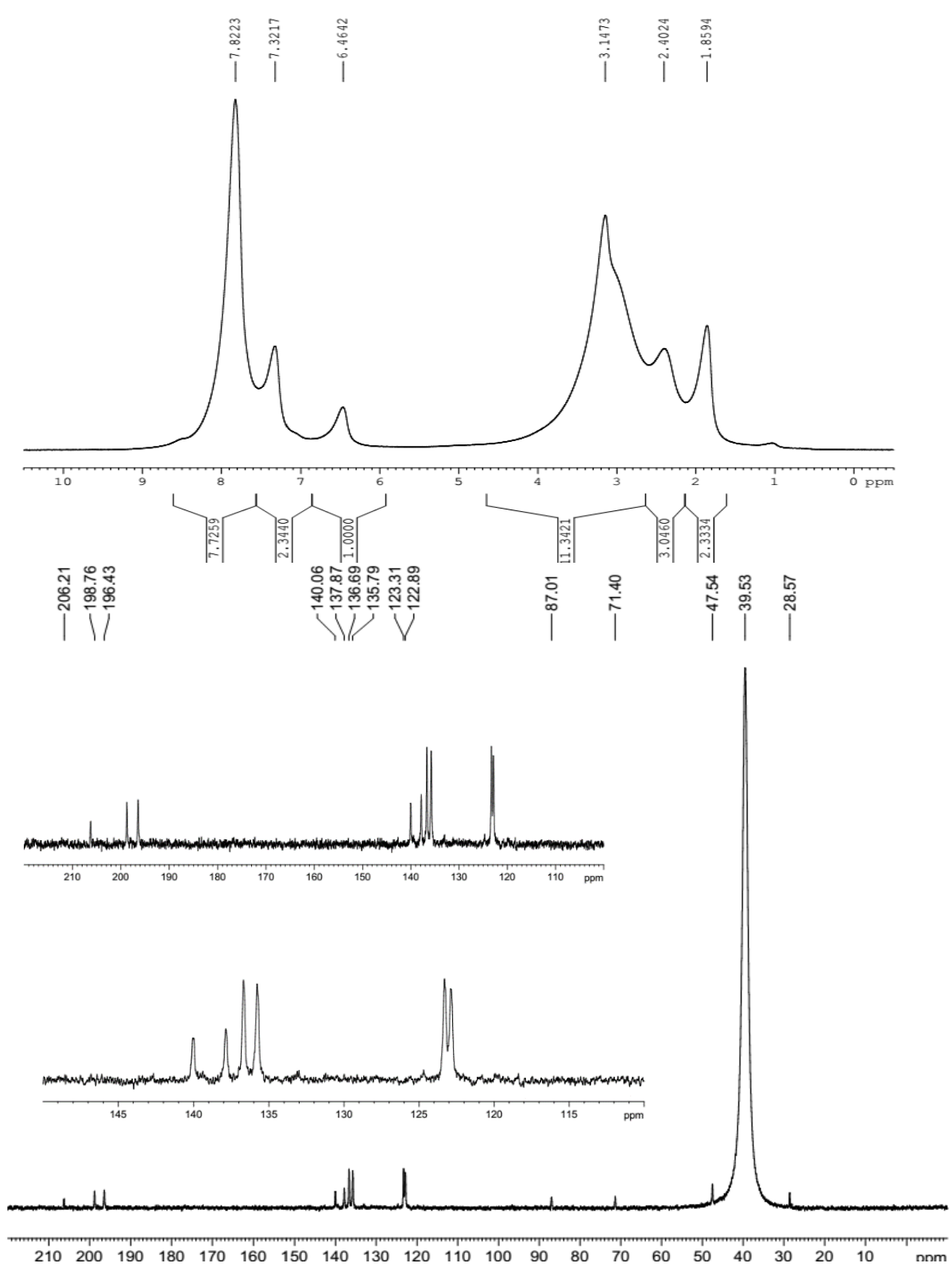

Figure $3 . \mathrm{H}^{1}$ and ${ }^{13} \mathrm{C}$ NMR spectral data of nickel(II)-nicotinic acid complex.

\section{CONCLUSION}

In terms of the nature of the metal ions: The stability constant of a trivalent metal ion increases with the increase of atomic number of the metal. The stability constant of divalent metal ion increases with decreasing of ionic radius of the metal ion, with copper as an exception due to

Bull. Chem. Soc. Ethiop. 2018, 32(3) 
Jahn-Teller effect. The trend of stability constants of divalent metal ions with ligand agrees with Irving-William series, $\mathrm{Cu}^{2+}>\mathrm{Ni}^{2+}>\mathrm{Co}^{2+}$. IR, raman and $\mathrm{NMR}$ spectral data confirmed the previous binding modes of nicotinic acid.

\section{ACKNOWLEDGMENTS}

The authors extend their appreciation to the Deanship of Scientific Research at King Khalid University, Abha, Saudi Arabia for funding this work through General Research Project under grant number G.R.P-16-38 (Bioinorganic Research Group).

\section{REFERENCES}

1. Chuck, R. Technology development in nicotinate production. Appl. Catal. A: Gen. 2005, 280, 75-82.

2. Allan, J.R.; Baird, N.D.; Kassyk, A.L. Some first row transition metal complexes of nicotinamide and nicotinic acid. J. Therm. Anal. Calorim. 1979, 16, 79-90.

3. Urbanska, J.; Podsiadly, H. Interaction of niacin with nickel(II) ions. J. Electroanal. Chem. 2009, 637, 55-62.

4. Szablowicz, M.; Kita, E. New chromium(III) - nicotinate complexes. Kinetics and mechanism of nicotinate ligand liberation in acidic media. Transit. Metal Chem. 2005, 30, 623-629.

5. Jingyan, S.; Jie, L.; Yun, D.; Ling, H.; Xin, Y.; Zhiyong, W.; Yuwen, L.; Cunxin, W. Investigation of thermal behavior of nicotinic acid. J. Therm. Anal. Calorim. 2008, 93, 403409.

6. Hughes, E.B.; Jellinek, H.H.G.; Ambrose, B.A. Nicotinic acid. Ultraviolet absorption spectrum and dissociation constants. J. Phys. Chem. 1949, 53, 414-423.

7. Coughlin, B.R.; Stone, A.T. Nonreversible adsorption of divalent metal ions $\left(\mathrm{Mn}^{\mathrm{II}}, \mathrm{Co}^{\mathrm{II}}, \mathrm{Ni}^{\mathrm{II}}\right.$, $\mathrm{Cu}^{\mathrm{II}}$ and $\mathrm{Pb}^{\mathrm{II}}$ ) onto goethite: Effects of acidification, $\mathrm{Fe}^{\mathrm{II}}$ addition and picolinic acid addition. Environ. Sci. Technol. 1995, 29, 2445-2455.

8. Anagnostopoulos, A.; Matthews, R.W.; Walton, R.A. Studies on metal carboxylates. Part II. cobalt(II) and nickel(II) complexes of certain pyridine carboxylic acids and pyridine-3sulfonic acid: Magnetic and spectral studies. Can. J. Chem. 1972, 50, 1307-1314.

9. Wu, C.D.; Lu, C.Z.; Zhuang, H.H.; Huang, J.S. Structure and magnetic property of a new 3D nicotinic acid bridged nickel polymer. Z. Anorg. Allg. Chem. 2003, 629, 693-696.

10. Ahuja, I.S.; Singh, R.; Rai, C.P. Complexes of copper(II) with nicotinic acid and some related ligands. Transit. Metal Chem. 1977, 2, 257-260.

11. Cooper, J.A.; Anderson, B.F., Buckley, P.D., Blackwell, L.F. Structure and biological activity of nitrogen and oxygen coordinated nicotinic acid complexes of chromium. Inorg. Chim. Acta 1984, 91, 1-9.

12. Abu-Youssef, M.A.M. Two new 3D network structures: $\left[\mathrm{Cd}_{3}(\mathrm{nic})_{4}\left(\mathrm{~N}_{3}\right)_{2}\left(\mathrm{H}_{2} \mathrm{O}\right)\right]_{\mathrm{n}}$ and $\left[\mathrm{Zn}(\mathrm{nic})\left(\mathrm{N}_{3}\right)\right]_{\mathrm{n}}(\mathrm{nic}=$ nicotinate anion). Polyhedron 2005, 24, 1829-1836.

13. Appleby, C.A.; Wittenberg, B.A.; Wiitenberg, J.B. Nicotinic acid as a ligand affecting leghrmoglobin structure and oxygen reactivity. Proc. Nat. Acad. Sci. USA 1973, 70, 564568.

14. Pan H.P.; Bai T.C.; Wang X.D. Density, viscosity and electric conductance of a ternary solution of (nicotinic acid + polyethanol + water). J. Chem. Eng. Data 2010, 55, 2257-2262.

15. Wierenga T.J.; Ivan L.J. Synthesis and characterization of cobalt(III) nicotinic acid complexes. Inorg. Chem. 1982, 21, 2881-2885.

16. Green C.A.; Bianchini R.J.; Legg J.I. Characterization of a stable chromium(III)nicotinic acid complex by deuteron NMR. Inorg. Chem. 1984, 23, 2713-2715.

17. Gerdom L.E.; Goff H.M. Ligation modes for nicotinic acid binding to the chromium(III)salen complex. Inorg. Chem. 1982, 21, 3847-3848 . 
18. Patil A.B. Mixed ligand complex studies of these metal ions using nitrilotriacetic acid. (NTA) and iminodiacetic acid (IMDA) as primary ligands and NA and AA as secondary ligands. Rasayan J. Chem. 2012, 5, 500-502 .

19. Rajhi, A.Y.; Ju, Y.-H.; Angkawijaya, A.E.; Fazary, A.E. Complex formation equilibria and molecular structure of divalent metal ions-vitamin B3-glycine oligopeptides systems. $J$. Solu. Chem. 2013, 42, 2409-2442.

20. Fazary, A.E.; Ju, Y.-H.; Rajhi, A.Q.; Alshihri, A.S.; Alfaifi, M.Y.; Alshehri, M.A.; Saleh, K.A.; Elbehairi, S.E.I.; Fawy, K.F.; Abd-Rabboh, H.S.M. Bioactivities of novel metal complexes involving B vitamins and glycine. Open Chem. 2016, 14, 287-298.

21. Fazary, A.E.; Bani-Fwaz, M.Z.; Fawy, K.F.; Sahlabji, T.; Awwad, N.S.; Abd-Rabboh, H.S.M. Norleucine metal complexes: Comments on their equilibrium constants data reviews in inorganic chemistry. 2018, 38, 43-48.

22. Fazary, A.E. Metal complexes of salicylhydroxamic acid and 1,10-phen-anthroline; equilibrium and antimicrobial activity studies. Bull. Chem. Soc. Ethiop. 2014, 28, 393-402.

23. Fazary, A.E.; Bani-Fwaz M.Z.; Fawy, K.F.; Abd-Rabboh, H.S.M. Levaquin drug complexing property towards platinum and palladium metal ions: Thermodynamic studies in aqueous solutions. J. Mol. Liq. 2018, 253, 178-187.

24. Fazary, A.E.; Fawy, K.F.; Bani-Fwaz, M.Z.; Sahlabji, T.; Abd-Rabboh, H.S.M. Thermodynamic studies on metal ions - Ninhydrin-glycine interactions in aqueous solutions. J. Chem. Thermodyn. 2018, 118, 302-315.

25. Fazary, A.E.; Ju, Y.-H.; Fawy, K.F.; Al-Shihri, A.S.; Bani-Fwaz, M.Z.; Alfaifi, M.Y.; Shati, A.A.; Elbehairi, S.E.I.; Abd-Rabboh, H.S.M. Nicotine-metal ion interactions in solutions: Potentiometric, cyclic voltammetry investigations and quantum chemical calculations. $J$. Chem. Thermodyn. 2017, 112, 283-292.

26. Fazary, A.E.; Alshihri, A.S.; Alfaifi, M.Y.; Saleh, K.A.; Elbehairi, S.E.I.; Fawy, K.F.; AbdRabboh, H.S.M. Gibbs energies of protonation and complexation of platinum and vanadate metal ions with naringenin and phenolic acids: Theoretical calculations associated with experimental values. J. Chem. Thermodyn. 2016, 100, 7-21.

27. Fazary, A.E.; Al-Shihri, A.S.; Saleh, K.A.; Alfaifi, M.Y.; Alshehri, M.A.; Elbehairi, S.E.I. Di- and tri-valent metal ions interactions with four biodegradable hydroxamate and cataecholate siderophores: New insights into their complexation equilibria. J. Solu. Chem. 2016, 45, 732-749.

28. Fazary, A.E.; Ju, Y.-H.; Rajhi, A.Q.; Alshihri, A.S.; Alfaifi, M.Y.; Alshehri, M.A.; Saleh, K.A.; Elbehairi, S.E.I.; Fawy, K.F.; Abd-Rabboh, H.S.M. Bioactivities of novel metal complexes involving B vitamins and glycine. Open Chem. 2016, 14, 287-298.

29. Rajhi, A.Y.; Ju, Y.-H.; Angkawijaya, A.E.; Fazary, A.E. Complex formation equilibria and molecular structure of divalent metal ions-vitamin B3-glycine oligopeptides systems. $J$. Solu. Chem. 2013, 42, 2409-2442.

30. Sadeek, S.A.; Zordok, W.A.; El-Attar, M.S.; Ibrahim, M.S. Spectroscopic, structural, thermal and antimicrobial studies of 4,6-bis(4-chlorophenyl)-2-oxo-1,2-dihydropyridine-3carbonitrile with some transition metals. Bull. Chem. Soc. Ethiop. 2015, 29, 75-94.

31. Moksharagni, B.; Hussain Reddy, K. Spectral characterization and DNA binding properties of lanthanide(III) complexes with 2-acetylpyridine isonicotinoylhydrazone (APINH). Bull. Chem. Soc. Ethiop. 2016, 30, 221-230.

32. Agarwal, R.K.; Agarwal, H.; Goel, N.; Sindhu, S.K. Synthesis and spectral studies of some lanthanide(III) complexes with 4-[N-( $p$-dimethylaminobenzalidene)amino] antipyrine semicarbazone. Bull. Chem. Soc. Ethiop. 2001, 15, 79-84.

33. Koczoń, P.; Dobrowolski, J.Cz.; Lewandowski, W.; Mazurek, A.P. Experimental and theoretical IR and Raman spectra of picolinic, nicotinic and isonicotinic acids. J. Mol. Struc. 2003, 655, 89-95. 